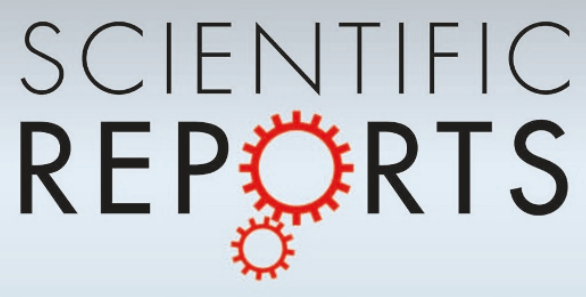

OPEN

SUBJECT AREAS:

MATERIALS FOR ENERGY AND CATALYSIS

MECHANICAL ENGINEERING

Received

4 August 2014

Accepted

16 December 2014

Published

19 January 2015

Correspondence and requests for materials should be addressed to V.I.L. (vlevitas@iastate.

edu)

\section{Pre-Stressing Micron-Scale Aluminum Core-Shell Particles to Improve Reactivity}

\author{
Valery I. Levitas' ${ }^{1}$, Jena McCollum² \& Michelle Pantoya ${ }^{2}$
}

${ }^{1}$ lowa State University, Department of Aerospace Engineering, Department of Mechanical Engineering, Department of Material Science and Engineering, Ames, lowa 5001 1, USA, ${ }^{2}$ Texas Tech University, Department of Mechanical Engineering, Lubbock, TX 79409, USA.

The main direction in increasing reactivity of aluminum $(\mathrm{Al})$ particles for energetic applications is reduction in their size down to nanoscale. However, Al nanoparticles are 30-50 times more expensive than micron scale particles and possess safety and environmental issues. Here, we improved reactivity of $\mathrm{Al}$ micron scale particles by synthesizing pre-stressed core-shell structures. Al particles were annealed and quenched to induce compressive stresses in the alumina passivation shell surrounding $\mathrm{Al}$ core. This thermal treatment was designed based on predictions of the melt-dispersion mechanism (MDM); a theory describing Al particle reaction under high heating rate. For all anneal treatment temperatures, experimental flame propagation rates for $\mathrm{Al}$ combined with nanoscale copper oxide $(\mathrm{CuO})$ are in quantitative agreement with the theoretical predictions based on the MDM. The best treatment increases flame rate by $36 \%$ and achieves $68 \%$ of that for the best $\mathrm{Al}$ nanoparticles.

R eaction of Al particles with various oxidizers is widely studied because $\mathrm{Al}$ fueled composites have high energy densities, especially in comparison to other fuels ${ }^{1}$. The primary direction in the development of $\mathrm{Al}$ particles in the last decade was reducing their size to the nanoscale (i.e., $\leq 100 \mathrm{~nm}$ in diameter), leading to three orders of magnitude reduction in ignition delay time ${ }^{2}$ and three orders of magnitude increase in flame propagation rate ${ }^{3-5}$ compared with their micron scale counterparts. Thus, flame rates reached about $1 \mathrm{~km} / \mathrm{s}$ for low density $\mathrm{Al}+\mathrm{MoO}_{3}$ and $\mathrm{Al}+\mathrm{Fe}_{2} \mathrm{O}_{3}$ nanopowders. Such significant increase in reactivity was rationalized by a new mechanochemical reaction mechanism coined the melt-dispersion mechanism $(\mathrm{MDM})^{6-8}$, which for fast heating rates substitutes the traditional diffusion mechanism ${ }^{9-12}$. The key point of the MDM is that $\mathrm{Al}$ melting is accompanied by a $6 \%$ volumetric expansion strain, which generates pressures of 1 to $3 \mathrm{GPa}$ in the molten $\mathrm{Al}$ core and tensile hoop stress $\sigma_{h}$ in the Al oxide shell that exceeds $10 \mathrm{GPa}$ and the ultimate strength of alumina $\sigma_{u}$. During fast heating and, consequently, loading, such stresses do not have time to relax and cause the dynamic fracture and spallation of the alumina shell. Spallation of the shell causes the pressure to approach zero at the bare Al surface, while pressure within the molten core does not initially change. This pressure imbalance produces an unloading spherical wave propagating to the center of the core, which generates a tensile pressure up to $8 \mathrm{GPa}$ at the center in the reflected wave. Such a pressure wave significantly exceeds the cavitation limit of liquid $\mathrm{Al}$ and disperses the $\mathrm{Al}$ core into small bare fragments, which fly at a high velocity. Thus, MDM transforms a single $\mathrm{Al}$ particle covered by an alumina shell into hundreds or thousands of smaller bare molten particles, and reaction is no longer limited by diffusion through the initial oxide shell.

In addition to some qualitative confirmation $s^{6-8,13-19}$, one of the main quantitative confirmations of the MDM is related to reproduction of a sophisticated relationship Eq.(1) between the relative flame propagation rate $V /$ $V_{\max }$ and the relative particle size $M=R / \delta[5-7]$. Here, $V$ is the flame propagation rate and $V_{\max }$ is the maximum possible flame propagation rate in the given experimental set-up under the same conditions (e.g., same initial bulk density of reactive mixture, oxidizer, stoichiometry, etc.); $R$ is the radius of the $\mathrm{Al}$ core and $\delta$ is the shell thickness.

Eq.(1) enabled predictions (e.g., that are exactly opposite to those based on the diffusion mechanism) and suggested methods to increase the flame propagation rate and particle reactivity. Since for large $M, V / V_{\text {max }}$ tends to a finite value (i.e., $0.4-0.5$ for $\mathrm{Al}$ ), activation of the $\mathrm{MDM}$ is anticipated for smaller-scale micron-Al particles (i.e., $<10$ microns). Indeed, a mixture of 1-3 micron diameter $\mathrm{Al}$ particles (i.e., $M=312$ to 438 ) with nanopolytetrafluoroethylene (PTFE) produced a relative flame rate $V / V_{\max }=0.463$, which practically coincides with the theoretically predicted value ${ }^{15}$. These studies suggest that micron-scale Al particles have the potential for demonstrating reactivity in accordance with the MDM. However, a mixture of the same Al particles with nanoscale $80 \mathrm{~nm}$ sized $\mathrm{MoO}_{3}$ produced flame rate of only half this value ${ }^{15}$. Recently ${ }^{19}, V / V_{\max }=0.42$ was obtained for similar micron particles but for $370 \mathrm{~nm}$ sized $\mathrm{MoO}_{3}$. 
Another prediction is that creating initial compressive stress in the shell and tensile stress in the core would delay shell fracture during heating and increase $V / V_{\max }{ }^{6}$. This was tested in Ref. 17 by producing $\mathrm{Al}$ particles that effectively manipulate residual stresses in the coreshell structures by applying annealing and quenching treatments. Specifically, MDM predicts increased reactivity of Al particles by increasing the temperature at which internal thermal stresses in the core - shell system are zero (i.e., $T_{0}$ ). Traditionally, $T_{0}$ coincides with the temperature at which the initial oxide shell is formed, i.e., room temperature. Keeping $\mathrm{Al}$ nano- and micron-scale particles at $378 \mathrm{~K}$ lead to relaxation of internal stresses and changed $T_{0}$ to $378 \mathrm{~K}^{17}$. For the fastest quench rate of $0.13 \mathrm{KPS}^{17}$, these stresses may not have time to relax during cooling and $T_{0}$ remained $378 \mathrm{~K}$. Such change in $T_{0}$ increased flame rate for $\mathrm{Al}+\mathrm{MoO}_{3}$ by $31 \%$ for nano-Al and by $41 \%$ for micron-Al particles, both in quantitative agreement with theoretical predictions.

It is noted that $\mathrm{Al}$ particles studied in Ref. 17 were initially not perfect. Specifically, the particle shells were synthesized in a partial nitrogen and oxygen containing environment. The influences of $\mathrm{Al}$ nitriding on alumina shell integrity are questionable. Because of this, untreated nanoparticles showed a flame rate of only $627 \mathrm{~m} / \mathrm{s}$ instead of $960 \mathrm{~m} / \mathrm{s}$ measured using the same set up and for the same conditions $s^{6,7}$ except with alumina shells formed in the absence of nitrogen. Also, untreated $\mathrm{Al}$ particles with 3-4.5 micron diameter produced a flame rate of $205 \mathrm{~m} / \mathrm{s}$, less than half of the theoretically predicted values. Also, attempt to increase $T_{0}$ to $443 \mathrm{~K}$ practically did not change flame rate for micron $\mathrm{Al}$ particles.

Some papers from other groups that criticized ${ }^{10,20}$ or supported ${ }^{14,16}$ the MDM are analyzed in detail in Ref. 19. The main conclusion was that different mechanisms (diffusive or MDM) can operate under different conditions. Since these conditions are far from being well defined or understood, observation of one of the mechanisms under some conditions compromises another one under the same conditions, but does not compromise for other conditions ${ }^{18}$. Thus, since $\mathrm{MDM}$ is in good correspondence with powder flame rate experiments ${ }^{6,7,15,17-19}$, failure to observe MDM in other conditions ${ }^{10,20}$ does not disapprove MDM. Further, contradictions found for the diffusion mechanism in the flame tube $e^{6,7,15,17-19}$ do not compromise it for conditions when it was indeed applicable $e^{9,10,12,20}$.

The main goal of this paper is to examine the potential to achieve increased reactivity using 3-4.5 micron diameter $\mathrm{Al}$ particles thermally treated to produce desired compressive stress in the alumina shell. The treated particles will be mixed with $\mathrm{CuO}$ and reactivity will be assessed using flame rate experiments. The main objectives are: (a) to reach the theoretically predicted flame rate for 3-4.5 micron $\mathrm{Al}$ particles mixed with $\mathrm{CuO}$, which is about half of the flame propagation rate of the best $\mathrm{Al}$ nanoparticles; and, (b) to demonstrate that these micron $\mathrm{Al}$ particle can be heat treated to increase $T_{0}$ to four values in a range 383-473 $\mathrm{K}$, after which they produce increased, theoretically predicted flame rates. Under the "best" particles and treatments we understand those exhibiting maximum flame rate. Both these objectives have been accomplished. The best treatment increases flame rate by $36 \%$ and reaches $68 \%$ of the flame rate of the best $\mathrm{Al}$ nanoparticles in the same set up. At the same time, micron particles are 30-50 times less expensive than nanoparticles and do not possess safety and environmental issues typical of nanoparticles. Note that in Ref. 17, $V / V_{\text {max }}=0.305$ was obtained for the best heat treatment, i.e., more than twice less than here.

\section{Results}

In Ref. 7, the following equation for the flame propagation rate $V$ was derived from the fracture criterion $\sigma_{h}=\sigma_{u}$ for alumina shell:

$$
\begin{aligned}
& V / V_{\max }=f ; \\
& f=\left(-B+\sqrt{B^{2}-4 A C}\right) / 2 A \text { for } 0<f \leq 1,
\end{aligned}
$$

where $f$ is the volume fraction of melt in Al core necessary to fracture of the oxide shell,

$$
\begin{array}{r}
A=6 \delta \varepsilon^{m} \Delta K\left(2+m^{3}\right) M G_{2} K_{2}, m=1+1 / M \\
B=2 \Gamma_{2} \Delta K m^{2}\left(2 G_{2}-3 K_{2}\right)+6 \delta\left(2+m^{3}\right) \\
M\left(\varepsilon^{m} K_{S}+\Delta \alpha \Delta K \Delta T\right) G_{2} K_{2} \\
-\delta \Delta K M\left(4 G_{2}+3 m^{3} K_{2}\right) \sigma_{u}, \\
C=6 \delta\left(2+m^{3}\right) M \Delta \alpha K_{S} \Delta T G_{2} K_{2} \\
-4\left(2+m^{3}\right) \Gamma_{1} G_{2} K_{2} \\
+2 \Gamma_{2} m^{2}\left(2 K_{S} G_{2}-3\left(K_{S}+2 G_{2}\right) K_{2}\right) \\
-M \delta \sigma_{u}\left(3 K_{S} K_{2} m^{3}+4 G_{2}\left(K_{s}+\left(m^{3}-1\right) K_{2}\right)\right) .
\end{array}
$$

In this equation, subscript 1 is for $\mathrm{Al}$ and 2 is for shell, Gand $K$ are the shear and bulk moduli, $K_{1}=f K_{1}^{m}+(1-f) K_{1}^{s}$ is the bulk modulus of Al melt-solid mixture, subscripts $s$ and $m$ are for the solid and melt phases, $\alpha$ is the linear thermal expansion coefficients, $T$ is the temperature, $T_{m}$ is the bulk melting temperature of $\mathrm{Al}$, and $3 \varepsilon^{m}$ the volumetric expansion during melting of $\mathrm{Al}, \Gamma_{1}$ and $\Gamma_{2}$ are the surface tensions at the aluminum-shell interface and shell-gas interface, $\Delta K=K_{1}^{m}-K_{1}^{s}, \Delta T=T-T_{0}$, and $\Delta \alpha=\alpha_{1}^{S}-\alpha_{2}$. All parameters in Eq.(1) can be found in Ref. 6.

Experimental methods for increasing temperature $T_{0}$ at which the core-shell structure is stress-free as well as methods of studying of flame propagation speed are presented in the Method section. Test conditions and results are summarized in Table 1 and also presented in Figs. 1 and 2. Theoretical curves in Figs. 1 and 2 are based on Eq.(1). Because $M$ varies from 374 (for $R=3 \mu \mathrm{m}$ and $\delta=4 \mathrm{~nm}$ ) to 1124 (for $R=4.5 \mu \mathrm{m}$ and $\delta=2 \mathrm{~nm}$ ), the experimental points are placed at these values (Fig. 1). Since for large $M$ flame rate weakly depends on $M$ (Fig. 1), this indeterminacy does not affect flame rate essentially. It is noted that the flame rate for nanoparticles with $\mathrm{M}=$ 13 to 19 (supplied by Novacentrix, with $R=38 \mathrm{~nm}$ and $\delta=2-3 \mathrm{~nm}$ ) is $558 \mathrm{~m} / \mathrm{s}$ and since $\mathrm{M}<19$, it will be considered as $V_{\text {max }}$ (see Refs. $6,7)$.

This value of $V_{\text {max }}$ is lower than for $\mathrm{Al}+\mathrm{MoO}_{3}$ mixture, and consistent with results in Ref. 21. Flame speed for untreated Al micron particles is $277 \pm 24 \mathrm{~m} / \mathrm{s}$, which gives a record value $V /$ $V_{\text {max }}=0.495$, which is even slightly higher than the theoretically predicted values of 0.469 for $M=375$ and 0.456 for $M=1124$.

Experimental points in Figs. 1 and 2 correspond to a maximum flame rate for each $T_{0}$, but do not always correspond to the maximum quench rate. Experimental points are very close to the theoretical predictions for each $T_{0}$. This correspondence strongly supports MDM and expands its area of validity to 3-4.5 micron diameter $\mathrm{Al}$ particles (i.e., for $M \leq 1124$ ) and for $\mathrm{CuO}$ oxidizer as well as for a broad range of $T_{0}$ from 296 to $473 \mathrm{~K}$.

Figure 2 shows relative flame rate $V / V_{\max }$ versus $T_{0}$ and gives additional insight. Since for untreated particles $V / V_{\max }$ was slightly higher than the theoretical value, the most probable reason is that the oxide shell had slightly higher strength. In all comparisons between experiments here and in Refs. 5-8,15,17 for nano and micron particles $\sigma_{u}=\sigma_{t h}$ was used, where $\sigma_{t h}=11.33 \mathrm{GPa}$ is the estimated theoretical strength of alumina. All our experimental points in Fig. 2 are within bands corresponding to $\sigma_{u}=(1 \pm 0.03) \sigma_{t h}$. This $3 \%$ difference is much smaller than indeterminacy of ultimate strength, which is strongly affected by defects and impurities. For $\mathrm{M} \rightarrow \infty$ and all material constants used in the paper, Eq.(1) reduces to the simple relationship

$$
V / V_{\max }=f=-1.052+0.103 \sigma_{u}+0.001127 \mathrm{~T}_{0} .
$$




\begin{tabular}{|c|c|c|c|}
\hline To (K) & Average Cooling Rate $(\mathrm{K} / \mathrm{s})$ & Avg Flame Rate $(\mathrm{m} / \mathrm{s})$ & Standard Deviation \\
\hline \multirow{3}{*}{$\begin{array}{l}296 \\
383\end{array}$} & & 277 & 24 \\
\hline & 0.16 & 272 & 5 \\
\hline & 0.46 & 287 & 23 \\
\hline 418 & 0.06 & 280 & 6 \\
\hline \multirow[t]{3}{*}{443} & 0.06 & 112 & 4 \\
\hline & 0.16 & 370 & 14 \\
\hline & 0.46 & 371 & 11 \\
\hline \multirow[t]{3}{*}{473} & 0.06 & 99 & 6 \\
\hline & 0.16 & 328 & 35 \\
\hline & 0.46 & 377 & 13 \\
\hline
\end{tabular}

Corresponding line in Fig. 2 is slightly below than for $\mathrm{M}=500$. Maximum relative flame rate of 0.676 is calculated for $T_{0}=473 \mathrm{~K}$ and is $36 \%$ higher than for the untreated particles. Thus, both formulated goals were achieved. Range of the effectiveness of the heat treatment to pre-stress particles was extended from $378 \mathrm{~K}$ to $473 \mathrm{~K}$ and improvement in reactivity was demonstrated in comparison with untreated particles exhibiting ideal (in accordance to theory) performance.

In regard to the effect of the quench rate, shown in Table 1 , for $T_{0}$ $=418$ and $473 \mathrm{~K}$ the highest flame rate results were achieved for the maximum quench rate $0.46 \mathrm{KPS}$, as expected from suppression of relaxation of internal stresses during cooling. At the same time, the highest flame rate for $T_{0}=443 \mathrm{~K}$ is obtained for the lowest quench rate $0.06 \mathrm{KPS}$. Finally, for $T_{0}=383 \mathrm{~K}$, maximum increase in the flame rate is found with the 0.16 KPS quench rate; results for 0.06 KPS are slightly lower, and for 0.46 KPS a small decrease in the flame rate is observed. Decrease in flame rate was observed for several other quench rates in Table 1 (including down to $112 \mathrm{~m} / \mathrm{s}$ for $T_{0}=443 \mathrm{~K}$ and $0.46 \mathrm{KPS}$ ), i.e., these treatments spoil the particles. Thus, there is no clear tendency in the effect of the quench rate on the flame propagation rate for all $T_{0}$. This implies that in addition to generation and relaxation of internal stresses, other processes take place. Thus, damage in the form of nanovoids, inclusions, or decohesion at Al-alumina interface and healing processes are possible. Aluminum may diffuse into the shell and react with oxygen within shell, producing additional internal stresses and damage.
Firmansyah et al. showed thickening of the shell for Al nanoparticles from 4.3 to $10 \mathrm{~nm}$ after heating to $933 \mathrm{~K}$ in Ar gas when oxidation should not to occur ${ }^{12}$. This was explained by diffusion of $\mathrm{Al}$ into the shell. Also, Al nanoparticles contain $\mathrm{B}, \mathrm{H}$, water, $\mathrm{Fe}, \mathrm{Cu}, \mathrm{K}$, and $\mathrm{N}$ impurities $^{22}$ and, the same may be true for micron particles. At elevated temperatures, these elements can diffuse into the shell changing its strength; some of them (e.g., $\mathrm{OH}$ ) and residual volatile organics may evaporate. Thus, further detailed studies are necessary to explain our results on the coupled effect of $T_{0}$ and the quench rate on stress development and strength of the shell and corresponding flame propagation rate.

The pressure in the $\mathrm{Al}$ core particle and the hoop stress in the alumina shell can be evaluated using Eqs. (1)-(3) in Ref. 6. We used $M=1000, \delta=2 \mathrm{~nm}$ (note that results weakly depend on $\delta$ ), and $f=$ 0 and zero gas pressure. For $T_{0}=T$, results show compressive pressure $p=2.09 \mathrm{MPa}$ in the core and a compressive hoop stress $\sigma_{h}=$ $-5.1 \mathrm{MPa}$ in the shell due to surface tension at the Al-alumina and alumina-gas interfaces. Heating to $T=473 \mathrm{~K}$ generates thermal tensile pressure $p=-6 \mathrm{MPa}$ within the core and compressive hoop stress in the shell of $\sigma_{h}=1.921 \mathrm{GPa}$. Changing $T_{0}$ to $473 \mathrm{~K}$ induces at room temperature $T=296 \mathrm{~K}$ tensile pressure $p=1.8 \mathrm{MPa}$ in $\mathrm{Al}$ and compressive stress $\sigma_{h}=-1.931 \mathrm{GPa}$ in a shell, which is $17 \%$ of $\sigma_{t h}$.

As it follows from Fig. 2 for $M=500$, the internal hoop stress of $-1.931 \mathrm{GPa}$ increases the theoretical volume fraction of the melt necessary to fracture the oxide shell $f=V / V_{\max }$ from 0.464 to

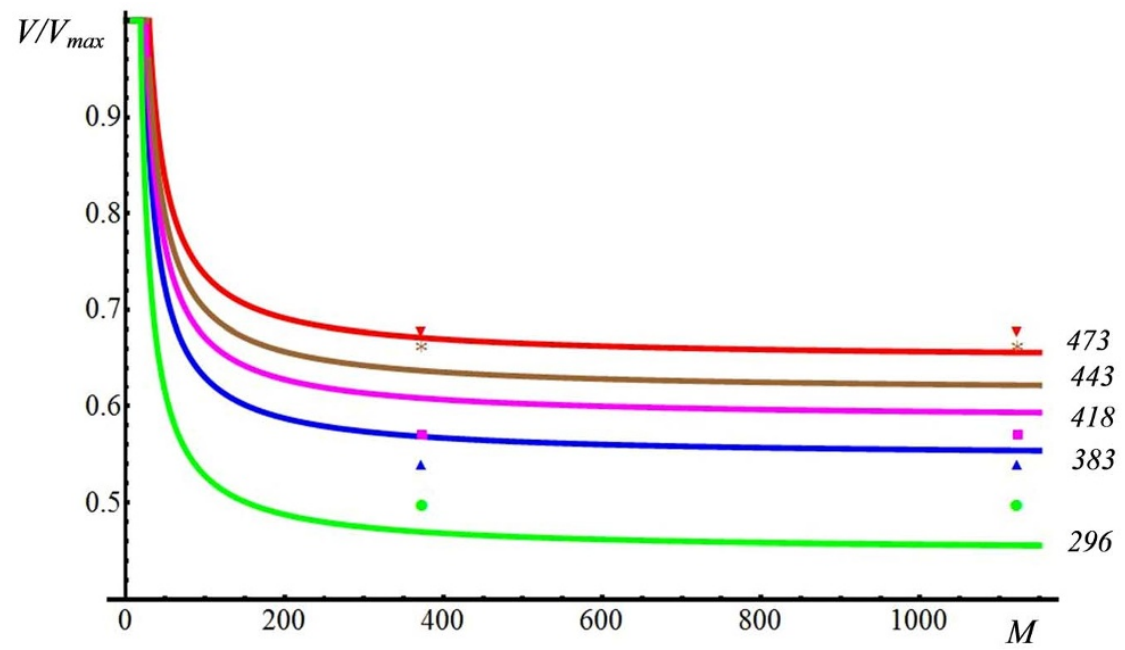

Figure $1 \mid$ Relative flame velocity $V / V_{\max }$ versus relative particle size $M=R / \delta$ for various values of temperatures $T_{0}(\mathrm{~K})$ (shown near the curves) at which core-shell structure is stress-free. Lines are calculated using Eq.(1). Symbols are experimental data for $T_{0}$ with the same color and sequence as the lines. 


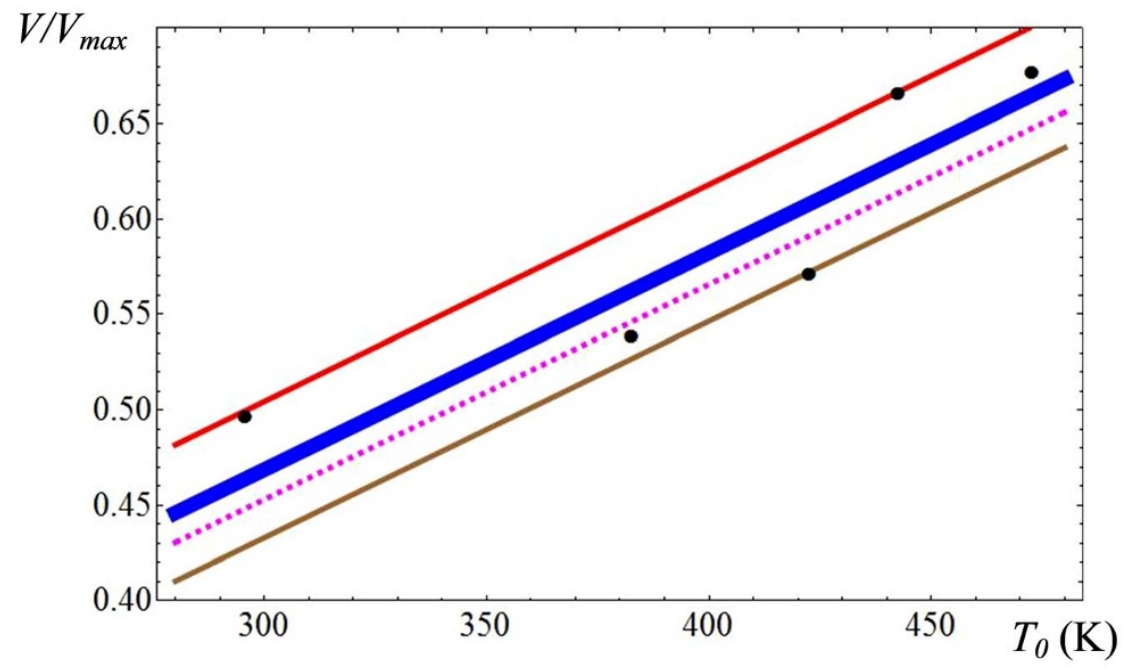

Figure $2 \mid$ Relative flame velocity $V / V_{\max }$ versus temperatures $T_{0}(\mathrm{~K})$ at which core-shell structure is stress-free. Dots are experimental results. Lines are calculated using Eq.(1). Thick line corresponds to $\sigma_{u}=\sigma_{t h}$ and $M=500$; upper and lower thin lines are for $M=500, \sigma_{u}=1.03 \sigma_{t h}$ and $\sigma_{u}=0.97 \sigma_{t h}$, respectively; dashed line is for $\sigma_{u}=\sigma_{t h}$ and $M=\infty$ (Eq. 2).

0.665 , i.e., by $45 \%$. Since untreated particles exhibited slightly better performance than predicted, increase in experimental value of the relative flame rate was $36 \%$.

If diffusion-based reaction mechanism is considered, then reduction in tensile stresses in a shell at high temperatures due to reduction in $T_{O}$ should reduce probability of damage and effective diffusion coefficient. Both should lead to reduced or unchanged (if these effects are small) flame speeds, which was not the case in these experiments (see Table 1). It is also noted that change in oxidizer from $\mathrm{MoO}_{3}$ in Refs. 15,17 to $\mathrm{CuO}$ resulted in the maximum relative flame rate predicted by MDM. This corroborates the important role the oxidizer has in promoting reactivity as suggested in Ref. 19, where the maximum flame rate predicted by MDM was achieved by increasing size of $\mathrm{MoO}_{3}$ particles. This is also consistent with the role of oxygen described in Refs. 23,24.

\section{Discussion}

Nontraditional ways to increase Al reactivity have been explored based on predictions from the recently developed MDM. In contrast to traditional directions (based on diffusion oxidation mechanism) that are to reduce particle size to $50-100 \mathrm{~nm}$, we suggest to increase particle size to 3-4.5 microns. The MDM theory predicts that flame rate for micron scale particles could reach $\sim 46 \%$ of the maximum flame rate of the best $\mathrm{Al}$ nanoparticles, while previous experiments for $\mathrm{Al}+\mathrm{MoO}_{3}$ mixture exhibited only half of this value. Here, a relative flame speed $V / V_{\max }=0.495$ was measured and is an even higher value than predicted, which may be related to an increase of the shell strength by $3 \%$. Thus, instead of using nanoparticles, micron scale $\mathrm{Al}$ particles show potential for enhanced reactivity and reduces the cost of particles by a factor of 30-50 as well as alleviates safety and environmental issues associated with nanoparticles. Also, nanoparticles possess a much larger concentration of initial alumina, which does not react, and is unfavorable for some weight-sensitive applications. Another MDM-based prediction suggests that producing preliminary compressive stress in a shell delays its fracture during high rate heating and further increases flame rate. In this study, the anneal temperature range $\left(T_{o}\right)$ was expanded to $473 \mathrm{~K}$, three quench rates in a broader range were evaluated, and the treated $\mathrm{Al}$ particles were mixed with nanoscale $\mathrm{CuO}$ and examined for flame rate. For the optimal quench rate for each $T_{0}$, experimental flame rates are in quantitative agreement with the theoretical predictions. For $T_{0}=$ $473 \mathrm{~K}$, flame rate increased by $36 \%$ and reached $68 \%$ of the flame rate of $\mathrm{Al}$ nanoparticles, which is more twice larger than in [17]. In addition to technical importance, obtained results strongly support MDM and expand its validity to micron-scale particles, $T_{0}$ up to $473 \mathrm{~K}$, and $\mathrm{CuO}$ oxidizer.

Further progress in resolving the role of mechanical properties in aluminum particle core-shell systems will require direct measurements of internal stresses using x-rays (like in Refs. 12,25) and finding the stress relaxation mechanism utilizing experiments and mechanochemical modeling similar $t^{26}$. Important basic and applied question is stability of internal stresses and their relaxation in time for different constant temperatures and accidental shortterm increase in temperature, and how stress relaxation affects particle performance (flame propagation rate, ignition delay time, and sensitivities to different stimuli). This will determine whether prestressing should be performed immediately before using particles or there is admissible storage time at different temperatures, including cryogenic temperatures for space applications. Of particular interest

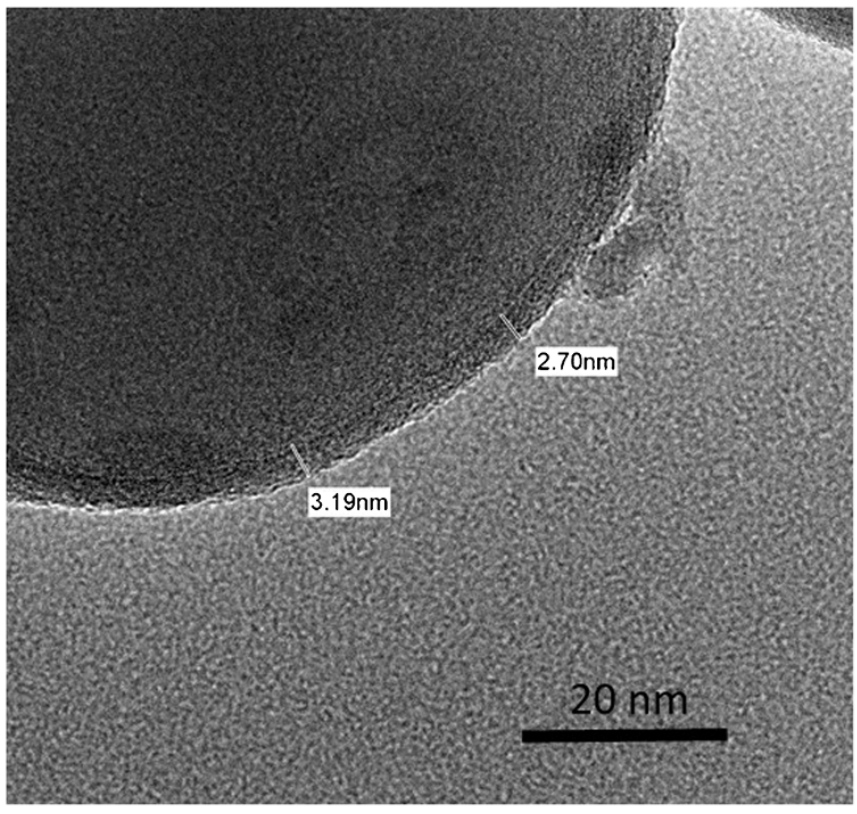

Figure $3 \mid$ High resolution TEM image for a single aluminum particle showing shell-core morphology. 

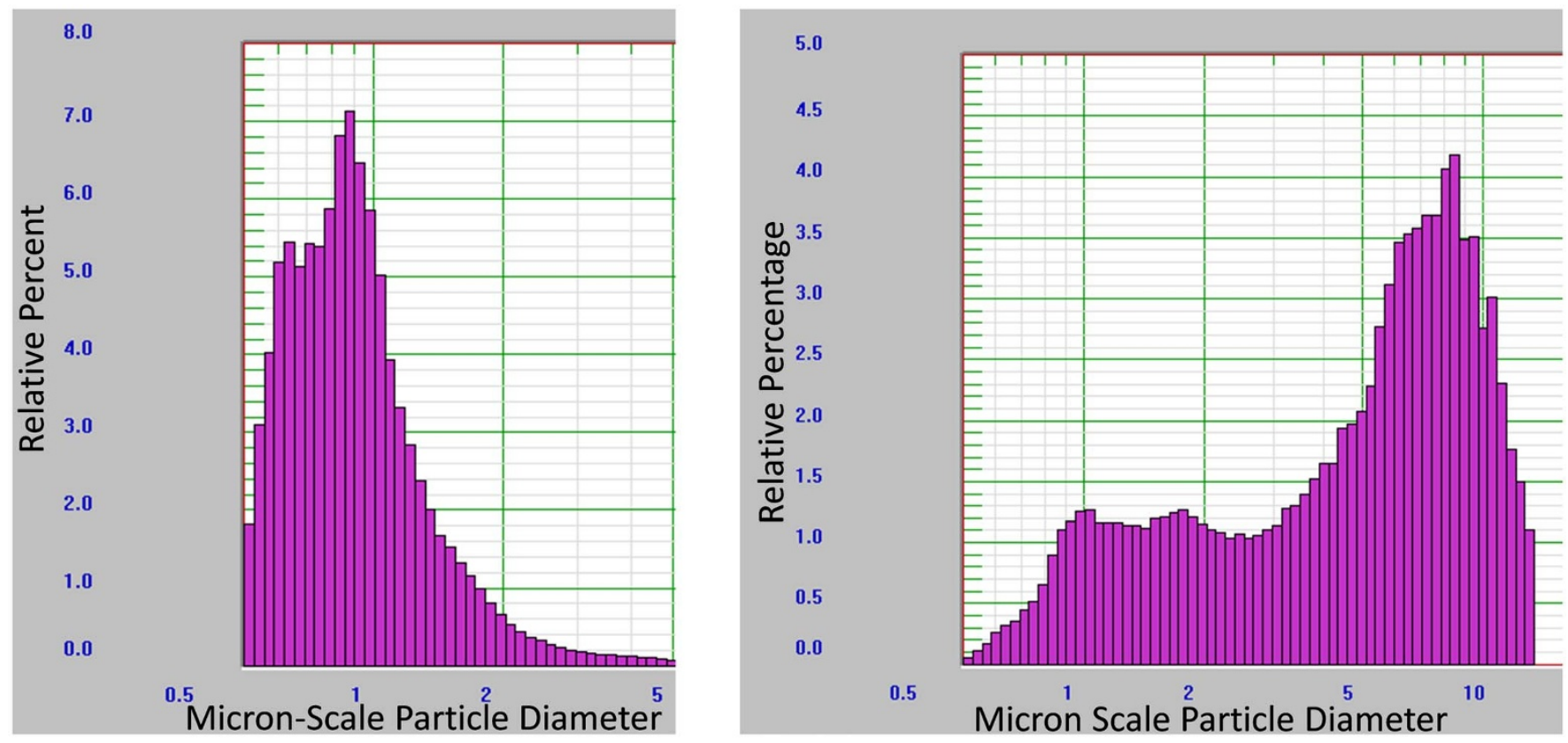

Figure $4 \mid$ Light scattering particle sizing for (a) number distribution and (b) volume distribution of particles.

is elucidating the non-monotonous effect of cooling rate on the flame speed.

While the focus of this paper was on increasing relative flame speed $V / V_{\max }$ based on the melt dispersion mechanism, there is a significant potential in increasing maximum flame speed $V_{\text {max }}$. In addition to parameters involved in Eq. (1) for $V / V_{\max }, V_{\max }$ may depend on the type, size, and geometry of the oxidizer particles, way of mixing $\mathrm{Al}$ and oxidizer, packing density, generated gas flows and mechanism of flame propagation (convective vs. conductive), ignition and reaction kinetics, heat losses, and others, which are not related to the MDM.

We also would like to mention that the MDM inspired development of other mechanisms to produce dispersion of initial product for increasing flame rate. Thus, it was suggested in Ref. 6 that an alternative way to cause the dispersion of fuel and oxidizer particles is to fabricate them with inclusions of a material that gasifies (or explodes) during heating, fracturing fuel and oxidizer particles. This principle was realized in producing micron scale composite particles consisting of $\mathrm{Al}$ and polytetrafluoroethylene $\mathrm{e}^{27}$ and $\mathrm{Al} /$ $\mathrm{CuO}$ and nitrocellulose ${ }^{28}$.

\section{Methods}

The particles chosen for this study were 3-4.5 micron average diameter $\mathrm{Al}$ and $50 \mathrm{~nm}$ average diameter $\mathrm{CuO}$ (both sizes are given by suppliers), both with spherical morphology. The Al particles were purchased from Alfa Aesar. The XRD data shows Al peaks and absence of other peaks, including alumina, which means that the alumina passivation shell is in the amorphous phase and there are no crystalline inclusions of other materials. Figure 3 shows a representative TEM image of the core-shell structure of an $\mathrm{Al}$ particle. The shell thickness varies along the edge of the particle and for different particles it is in the range between 2 and $4 \mathrm{~nm}$. Note that results for flame propagation speed weakly depend on $\delta$ and $M$ (Fig. 1). Also, dynamic and static light scattering analysis for particle sizing indicates that the number distribution shows a mean diameter of 1.02 microns (Fig. 4a) while the volume distribution shows a mean diameter of $5.52 \mathrm{~nm}$ (Fig. 4b). The distribution we report is in the range between 3 4.5 microns between both number and volume analyses. It is noted that while less than $0.5 \%$ have particle diameters greater than 6 microns, these particles have a significant effect on the overall volume percent and provide $43 \%$ of the total powder volume. However, if these particles would not react within flame front, they would represent dead weight and significantly decelerate flame speed, which is not the case in our study. Also, the supplier reports pure aluminum concentration as $98 \mathrm{wt} \%$ such that the metal oxide composes $2 \mathrm{wt} \%$ of the powder. The $\mathrm{CuO}$ nanoparticles were provided by Sigma Aldrich. The powders were mixed to an equivalence ratio of 1.2 using the same procedure described in [17].

The same method of increasing $T_{0}$ shown in Ref. 17 was also used here. Particles were heated to prescribed temperatures and held (annealed) for 10 minutes, which is predicted to be sufficient duration for complete relaxation of internal stresses due to inelastic processes in the shell. This temperature is then equal to $T_{0}$ by definition. To keep this $T_{0}$ during quenching to room temperature, the quench rate should be fast to shorten time during which particles are at elevated temperature and new thermal stresses due to difference $T-T_{0}$ do not relax ${ }^{17}$.

Flame propagation rate measurements were performed using semi-confined burn tubes identical to those described in [17] and prepared with an average of $550 \mathrm{mg}$ (and $15 \%$ of theoretical maximum density) powder mixture. Once filled, the tubes were sealed with electrical tape and a Nickel-Chromium wire to trigger ignition. All flame rate tests were performed in triplicate to establish repeatability of the measurements. This is reported as the standard deviation among the three tests performed for each data point. Repeatability is the largest source of uncertainty in the reported data.

The tubes were placed in a metal block housed in a blast chamber for annealing. An electric heating coil was positioned around the metal block and heated to the following temperatures: $T_{0}=383,418,443$, and $473 \mathrm{~K}$. The tubes were inserted into the block for heating and temperature was monitored using a type $\mathrm{K}$ Omega ${ }^{\odot}$ precision fine wire thermocouple. The same type of thermocouple was used to monitor the heating and quench rates of the powders. The sample tubes were brought to the anneal temperature and maintained for 10 minutes. The tubes were then subjected to three different quench rates. The first quench rate was achieved by removing the heated tube from the block and blast chamber and placing it in a refrigerator until the powder reached ambient temperature, $T_{a}$, which was $276 \mathrm{~K}$ in refrigerator and $306 \mathrm{~K}$ near heater. This produced an average quench rate of $0.46 \mathrm{KPS}$ (calculated as $T_{0^{-}}$ $1.01 T_{a}$ divided by cooling time to reach $1.01 T_{a}$ ). The second quench rate was achieved by removing the tube from the block and blast chamber and allowing it to cool at room temperature, producing an average quench rate of $0.16 \mathrm{KPS}$. The final quench rate was achieved by cutting the power supply to the coil and allowing the tube to cool in the block and blast chamber, producing a quench rate of 0.06 KPS. Our estimates indicate that in the natural convection conditions that exist in these experiments $\mathrm{Bi}$ number varies from 0.017 to 0.008 in temperature range from $298 \mathrm{~K}$ to $473 \mathrm{~K}$. Since $\mathrm{Bi}<0.1$ these powders behave according to a lump capacitance model. Experimental temperature evolution is well-approximated by an exponential function that further confirms lumped capacitance model. The temperature evolution reduces exponentially and experimental results are approximated by $T=T_{a}+\left(T_{0}-T_{a}\right) \exp (-A t)$ with three values of $A$ consistent with our average quench rate. Thus, an averaged $A=$ $0.013 s^{-1}$ for the highest quench rate, $A=0.005 s^{-1}$ for the intermediate quench rate, and $A=0.002 \mathrm{~s}^{-1}$ for the lowest cooling. The blast chamber and block were cooled to room temperature before igniting the samples.

We suspected that stresses will relax in time at room and especially at elevated temperature; however, temperature-dependent stress relaxation rate is unknown and will be studied in future experiments. To reduce/eliminate the effect of stress relaxation of flame speed, flame propagation experiments have been performed immediately after quenching. That is why particles have not been characterized after heat treatment.

1. Fischer, S. H. \& Grubelich, M. C. Theoretical energy release of thermites, intermetallics, and combustible metals. Paper presented at $24^{\text {th }}$ Int. Pyrotechnics Seminar: Monterey, CA, 1998, July 27- 31. Chicago: IL, USA: IIT Research Inst., 231-286 (1998). 
2. Granier, J. J. \& Pantoya, M. L. Laser ignition of nanocomposite thermites. Combust. Flame 138, 373-383 (2004).

3. Bockmon, B. S., Pantoya, M. L., Son, S. F., Asay, B. W. \& Mang, J. T. Combustion velocities and propagation mechanisms of metastable interstitial composites. I. Appl. Phys. 98, 064903 (2005).

4. Yarrington, C. D., Son, S. F., Foley, T. J., Obrey, S. J. \& Pacheco, A. N. Nano Aluminum Energetics: The Effect of Synthesis Method on Morphology and Combustion Performance. Propellants, Explosives, Pyrotechnics 36, 551-557 (2011).

5. Malchi, J. Y., Yetter, R. A., Son, S. F. \& Risha, G. A. Nano-aluminum flame spread with fingering combustion instabilities. Proc. Combust. Inst., 31, 2617-2624 (2007).

6. Levitas, V. I., Asay, B. W., Son, S. F. \& Pantoya, M. Mechanochemical mechanism for fast reaction of metastable intermolecular composites based on dispersion of liquid metal. J. Appl. Phys. 101, 083524 (2007).

7. Levitas, V. I., Pantoya, M. L. \& Dikici, B. Melt dispersion versus diffusive oxidation mechanism for aluminum nanoparticles: Critical experiments and controlling parameters. Appl. Phys. Lett. 92, 011921 (2008).

8. Levitas, V. Burn time of aluminum nanoparticles: Strong effect of the heating rate and melt-dispersion mechanism. Combust. Flame 156, 543-546 (2009).

9. Rosenband, V. Thermo-mechanical aspects of the heterogeneous ignition of metals. Combust. Flame 137, 366-375 (2004).

10. Chowdhury, S., Sullivan, K., Piekiel, N., Zhou, L. \& Zachariah, M. R. Diffusive vs Explosive Reaction at the Nanoscale. J. Phys. Chem. C 114, 9191-9195 (2010).

11. Trunov, M. A., Schoenitz, M., Dreizin, E. L. Effect of Polymorphic Phase Transformations in Alumina Layer on Ignition of Aluminum Particles Combust. Theory Model. 10, 603 (2006).

12. Firmansyah, D. A. et al. Microstructural Behavior of the Alumina Shell and Aluminum Core Before and After Melting of Aluminum Nanoparticles. J. Phys. Chem. C, 116, 404-411 (2012).

13. Pantoya, M. L., Levitas, V. I., Granier, J. J. \& Henderson, J. B. The effect of bulk density on the reaction dynamics in nano and micron particulate thermites. J Propul. Power, 25, 465 (2009).

14. Ohkura, Y., Rao, P. M. \& Zheng, X. Flash ignition of Al nanoparticles: Mechanism and applications. Combust. Flame 158, 2544-2548 (2011).

15. Levitas, V. I., Pantoya, M. L. \& Watson, K. W. Melt-dispersion mechanism for fast reaction of aluminum particles: Extension for micron scale particles and fluorination. Appl. Phys. Lett. 92, 201917 (2008)

16. Comet, M., Siegert, B., Pichot, V. \& Spitzer, D. Reactive characterization of nanothermites. Correlation structure/reactivity. J. Therm. Anal. Calorim. 111, 431-436 (2013).

17. Levitas, V. I., Dikici, B. \& Pantoya, M. L. Toward design of the pre-stressed nanoand microscale aluminum particles covered by oxide shell. Combust. Flame 158, 1413-1417 (2011).

18. Levitas, V. I. Mechanochemical mechanism for reaction of aluminium nano- and micrometre-scale. Phil. Trans. R. Soc. A 371, 20120215 (2013)

19. Levitas, V. I., Pantoya, M. L. \& Dean, S. Melt dispersion mechanism for fast reaction of aluminum nano- and micron-scale particles: Flame propagation and SEM studies. Combust. Flame 161, 1668-1677 (2014).
20. Lynch, P., Fiore, G., Krier, H. \& Glumac, N. Gas-phase Reactions in the Combustion of Nano-aluminum Combust. Sci. Technol. 182, 842 (2010).

21. Sanders, V. E. et al. Reaction propagation of four energetic composites ( $\mathrm{Al} / \mathrm{MoO} 3$, Al/WO3, Al/CuO, and Bi2O3). J. Propul. Power, 23, 707-714 (2007).

22. Ramaswamy, A. L. \& Kaste, P. J. A "Nanovision" of the Physiochemical Phenomena Occurring in Nanoparticles of Aluminum. J. Energ. Mater. 23, 1 (2005)

23. Zhou, L., Piekiel, N., Chowdhury, S., \& Zachariah, M. R. Time-Resolved Mass Spectrometry of the Exothermic Reaction between Nanoaluminum and Metal Oxides: The Role of Oxygen Release. J. Phys. Chem. C 114, 14269-14275 (2010).

24. Jian, G., Chowdhury, S., Sullivan, K. \& Zachariah, M. R. Nanothermite reactions: Is gas phase oxygen generation from the oxygen carrier an essential prerequisite to ignition? Combust. Flame 160, 432-437 (2013).

25. Pratt, A., et al. Enhanced Oxidation of Nanoparticles through Strain-Mediated Ionic Transport. Nature Mat. 13, 26-30 (2014).

26. Levitas, V. I. \& Attariani, H. Mechanochemical Continuum Modeling of Nanovoid Nucleation and Growth in Reacting Nanoparticles. J. Phys. Chem. C 116, 54-62 (2012).

27. Sippel, T. R., Son, S. F. \& Groven, L. J. Aluminum agglomeration reduction in a composite propellant using tailored Al/PTFE particles. Combust. Flame 161, 311-321 (2014)

28. Wang, H., Jian, G., Egan, G. C. \& Zachariah, M. R. Assembly and reactive properties of $\mathrm{Al} / \mathrm{CuO}$ based nanothermite microparticles. Combust. Flame 161, 2203-2208 (2014).

\section{Acknowledgments}

The grant from ONR (N00014-12-1-0525) managed by Dr. C. Bedford is gratefully acknowledged.

\section{Author contributions}

V.I.L. developed and analyzed theory. J.M. and M.P. performed the experiments.

\section{Additional information}

Competing financial interests: The authors declare no competing financial interests.

How to cite this article: Levitas, V.I., McCollum, J. \& Pantoya, M. Pre-Stressing Micron-Scale Aluminum Core-Shell Particles to Improve Reactivity. Sci. Rep. 5, 7879; DOI:10.1038/srep07879 (2015)

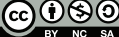

This work is licensed under a Creative Commons Attribution-NonCommercialShareAlike 4.0 International License. The images or other third party material in this article are included in the article's Creative Commons license, unless indicated otherwise in the credit line; if the material is not included under the Creative Commons license, users will need to obtain permission from the license holder in order to reproduce the material. To view a copy of this license, visit http:// creativecommons.org/licenses/by-nc-sa/4.0/ 